\title{
Should the general curriculum of medical schools include teaching in 'alternative medicine'?
}

F.R. Rosendaal

Teaching medical students about alternative and complementary medicine is as useful as teaching astronomers about the signs of the zodiac, oil drillers about dowsing or stock brokers about clairvoyance. After centuries of medicine governed by magical thinking and witchcraft, it was only a relatively short time ago that we embraced the concept of sciencebased and evidence-based medicine, and nothing is to be gained by returning to the dark ages of superstition and miracle cures.

The scientifically inclined reader may be interested in a definition of alternative medicine, which is not straightforward, compare, for example, vitamin therapy for homocystinaemia (vitamin B) or for the prevention of the common cold or ageing (vitamins $\mathrm{C}$ and $\mathrm{E}$ ). A definition that seems relevant in the present context is that of therapies and interventions not taught at medical schools. ${ }^{1}$ A non-exhaustive list includes magnetism, naturopathy, chiropractic medicine, herbalism, traditional Chinese medicine, Unani, Ayurveda, qi gong, Reiki, aromatherapy, biofeedback, neuroprogramming, hypnosis, homeopathy, acupuncture, acupressure, mental healing, voodoo, interventional prayer, or, in short, everything that used to be called quackery.

Alternative medicine does not work and cannot work. If it did, it would be regular medicine and taught at medical schools. That does not mean, however, that alternative medicine is always harmless, for it can do harm and likewise including it in the medical curriculum will have negative consequences: it will harm the acquisition of academic thinking, the foremost goal of an academic education. In order to explain what academic thinking is and why alternative medicine is fundamentally alien to it, we have to look at science and how it progresses.

Medical school offers an academic environment in which students are educated and trained to become physicians. This is somewhat different from purely academic schooling, as in mathematics or medieval French, or purely vocational training, as in gardening or plumbing, although one could easily argue that all practical schooling, of whatever level, requires some theoretical framework. 'Academic' implies acquiring understanding of how science moves forward: how theories are proposed and tested, established when corroborated by empirical evidence and sometimes proved wrong by newer theories or experiments. Isaac Newton's theory of mechanics was superseded by the relativity physics of Albert Einstein, three centuries later. Theories cannot be proven conclusively, but, as Karl Popper has taught us, they can only be falsified. The true scientific mind is critical towards its own hypotheses and seeks to disprove them. In so far as serious research is being done by those who adhere to theories of alternative medicine, it is to prove that these theories are right, so that a negative outcome of such studies is a priori unacceptable to them. This shows a fundamentally unacademic mindset.

Science has often been likened to a large building, to which each researcher 
makes some addition or small modification and in this way the building at the same time grows and is remodelled. Or, as Bernhard de Chartres put it, we are 'nanos gigantum humeris insidentes' (dwarves sitting on the shoulders of giants). Not so with alternative medicine: the theory of homeopathy is simply the childish belief that small quantities of a deleterious substance can cure diseases that resemble poisoning with that same substance; a theory which has no footing in biochemistry and which has not shown any development or growth since it was first postulated. ${ }^{2}$ Acupuncture is based on a theory of 'meridians' that have no basis in anatomy and defy all logic. In other worlds, the building was suddenly there, rather than having been built slowly, and it has not been improved over time. Those who believe in alternative medicine, indeed only 'believe', the word itself indicating we are not dealing with a rational science-based viewpoint. One rarely hears physicists declare that they 'believe' there might be such a thing as gravity or surgeons stating that they 'believe' that there might be some good in repositioning broken bones (the word 'believe' may be used by scientists, but only to indicate a degree of uncertainty around a scientific matter, which is exactly the opposite of the belief we are discussing here, which rather resembles religious beliefs).

Richard Dawkins gives a beautiful example of the academic mindset when he tells the story of a professor at the Zoology department in Oxford, who did not believe the Golgi apparatus existed: "For years he had passionately believed and taught that the Golgi apparatus (a microscopic feature of the interior of cells) was not real: an artifact, an illusion. Every Monday afternoon it was the custom of the whole department to listen to a research talk by a visiting lecturer. One
Monday, the visitor was an American cell biologist who presented completely convincing evidence that the Golgi apparatus was real. At the end of the lecture, the old man strode to the front of the hall, shook the American by the hand and said - with passion - 'My dear fellow, I wish to thank you. I have been wrong these fifteen years."'3

Science has two pillars: theory and experimentation, which are intertwined like the two strands of DNA: theory leads to experimentation, which will corroborate or refute it, and this will lead to new theories. Some theories are very fundamental and it would require an even more fundamental theory and convincing experimentation to overthrow it, as relativity did with Newtonian mechanics. Take for instance homeopathy: to accept that a substance diluted quadrillion-fold would exert action because of the way it is shaken at each dilution, we would need to reject the most fundamental chemical theories. Even a well-performed study showing a clinical effect of homeopathy in a clinical trial would not be strong enough evidence to do this.

Should medical students not learn to have an open mind? Sure. They need to be critical and they need to question theories. Uncritical belief in the unfounded theories of alternative medicine, however, is the opposite of having an open mind. Or, as Oberg said: "It is good to have an open mind, but not so open your brains fall out." Medical students need to learn academic thinking, need to understand how science is a building of theory strutted by experimentation and none of this requires teaching of alternative medicine.

As I mentioned above, medical training is not only academic but also practical. Medical students need to learn to diagnose and treat patients. They need to 
learn how to communicate with patients and above all they need to learn empathy. They will need to know the limitations of their own skills and of modern medicine. Perhaps the most difficult lesson will be that there are patients whom they can offer very little. Hopefully, they will learn modesty, humility and tolerance, also when their patients wish to visit providers of alternative therapies. And this is the only reason why some teaching of alternative medicine may be included in the curriculum, for doctors to understand their patients and to be able to inform them fully about the dangers inherent in some 'therapies'. However, there is no reason at all to teach students about the socalled underlying principles of alternative medicine, no reason to teach them about meridians or endless solutions. Why? Because there is no scientific basis for these 'principles.'

That is, of course, if you as a teacher accept that alternative medicine is non-existent. If you believe otherwise, you should go back to your chemistry and biology books and acquire an academic mindset.

\section{References}

1. Eisenberg DM, Kessler RC, Foster C, Norlock FE, Calkins DR, Delbanco TL. Unconventional medicine in the United States. Prevalence, costs, and patterns of use. N Engl J Med. 1993;328:246-52.

2. Goldacre B. Bad Science. London: Fourth Estate; 2009 (pp28-63).

3. Richard Dawkins. The God Delusion. London: Bantam Press; 2006.

The author

F.R. Rosendaal, MD PhD, is clinical epidemiologist and professor Department of Clinical Epidemiology, Leiden University Medical Center Leiden, the Netherlands.

Correspondence

Prof. dr. F.R. Rosendaal, Clinical Epidemiology, C7-P, Leiden University Medical Center, P.O. Box 9600, 2300 RC Leiden, the Netherlands.

E-mail:f.r.rosendaal@lumc.nl

No potential conflict of interest relevant to this article was reported 